\title{
Fake news: fronteiras do jornalismo e circulação de (des)informação sobre saúde
}

\section{Fake news: journalism frontiers and spread of desinformation about health}

\section{Fake news: fronteras del periodismo y propagación de la desinformación sobre salud}

Marco Antônio Roxo da Silva ${ }^{1, a}$

Editor convidado

marcos-roxo@uol.com.br | https://orcid.org/oooo-0001-5398-622X

Seane Alves Melo ${ }^{1, b}$

Editora convidada

seanemelo@gmail.com | https://orcid.org/0000-0001-9513-3946

${ }^{1}$ Universidade Federal Fluminense, Departamento de Estudos Culturais e Mídia. Niterói, RJ, Brasil.

a Doutorado em Comunicação pela Universidade Federal Fluminense.

b Mestrado em Ciências da Comunicação pela Universidade de São Paulo.

Palavras-chave: Fake news; Hiperjornalismo; Sistema do jornalismo profissional; Saúde; Outsiders.

Keywords: Fake news; Hyperjournalism; Professional journalism system; Health; Outsiders.

Palabras clave: Fake news; Hiperperiodismo; Sistema del periodismo profesional; Salud; Outsiders.

O que são fake news? De que forma este fenômeno afeta a produção de notícias em geral e, em particular, as relacionadas à saúde? Há geralmente a ideia de que fake news são 'notícias falsas'. Mas este é um eufemismo duvidoso. Se são falsas, por que afetam tanto nossa realidade? Por que os serviços de factchecking não conseguem detê-las e identificá-las em sua plenitude? As respostas a estas perguntas exigem um outro olhar sobre o fenômeno, que contemple uma reflexão sobre as diversas práticas comunicacionais que ampliaram as fronteiras profissionais do jornalismo.

Tal fenômeno está relacionado a práticas como o videojornalismo ${ }^{1}$, um tipo de produção de imagem testemunhal, orientada pela lógica do "aqui e agora", porém mais subjetiva e, portanto, distante dos códigos compartilhados pelo telejornalismo convencional ${ }^{1}$, e sua referência aqui no Brasil é o Mídia Ninja. Envolve também o deslocamento de jornais impressos e televisivos para plataformas online, impondo 
uma concorrência pelo furo e pela produção de notícias em tempo real, bem como desnudando rotinas produtivas antes inacessíveis ao público².

Essesprocessosacabaramporfacilitarodomíniodoprocessonoticiosopordiletantese, consequentemente, tornaram possível o fenômeno das fake news ${ }^{3-5}$. Partimos, então, da premissa de que as tensões envolvendo as fronteiras da comunidade jornalística profissional e as fake news dizem respeito a um alargamento das práticas jornalísticas representadas pelo termo "hiperjornalismo" "-7. É preciso afirmar tratar-se de um termo contextual, isto é, uma expressão que marca uma leitura diferente dos atravessamentos entre o jornalismo e outras áreas - leitura na qual se enfatizam os impactos culturais do jornalismo em outros campos de produção, como o entretenimento ${ }^{6}$ e até mesmo a saúde. A presença de profissionais médicos em diversos tipos de programas de entrevistas, como o de Ana Maria Braga, é um exemplo disso.

Assim, não podemos menosprezar a influência cultural dos textos e imagens que circulam em vídeos em plataformas como o Youtube, a proliferação dos comentários e análises em blogs, bem como do desdobramento de técnicas do jornalismo, como as entrevistas, os reality shows, os talk shows e outros tipos de produções circulantes no ambiente digital. Nosso argumento é de que essa pujança informativa vem acompanhada de mudanças tecnológicas que reduzem as assimetrias entre jornalistas e sua audiência, e que isso é uma chave importante para compreendermos a presença de outsiders e outros agentes até então residuais na prática jornalística dentro da produção noticiosa.

Um dos aspectos que chama atenção é a circularidade dos jornalistas e outsiders por diversas plataformas, sendo alguns colunistas de jornais impressos, apresentadores de programas de TV e, ao mesmo tempo, blogueiros. Segundo $\mathrm{Neveu}^{8}$, isso revela a vocação mestiça do jornalismo, mas ao mesmo tempo expõe esses agentes às críticas e comentários de pares e de outsiders, além de mostrar particularidades do trabalho jornalístico para além das reportagens e coberturas diárias (hard news), nas quais o debate acerca da legitimidade do que é dito por esses agentes é pouco ou nada explorado.

Zelizer $^{9}$ (p. 11) é uma das autoras que defende que o sistema profissional do jornalismo se orienta pela capacidade que têm os jornalistas de se afirmarem como porta-vozes legítimos e confiáveis dos eventos da "vida real". Mas essa capacidade não está institucionalizada como parte da profissão. Para a autora, ela é fruto da capacidade que têm os jornalistas de utilizar os códigos de conhecimento coletivo na produção e padronização de suas narrativas. Uma vez que o jornalismo apresenta a característica de não ser uma profissão tão formalizada quanto outras, o uso padronizado desses códigos faria a comunidade jornalística funcionar como uma comunidade interpretativa ${ }^{\mathrm{i}}$.

Carlson $^{10}$, por sua vez, concorda, mas ressalta que esse processo tem fragilidades acentuadas diante dos desafios atuais do jornalismo. Isto ocorre porque o suposto direito do jornalista profissional de ser ouvido, visto ou lido se dá, atualmente, dentro do contexto de relações menos assimétricas por meio da enunciação de um discurso. Isto, por sua vez, exige um dado controle sobre um conhecimento particular, mais sujeito a uma contestação, em virtude dos seus modos de legitimidade. $O$ argumento diz respeito ao abalo que, de certa forma, a extrema capilaridade do circuito comunicativo provoca com os dispositivos online, móveis e digitais.

Os blogs podem ser vistos como um exemplo da capacidade de apropriação dos códigos e convenções jornalísticos mais institucionalizados por outsiders e da tensão que isso traz ao processo de afirmação da autoridade do sistema profissional do jornalismo - até então, o principal mediador da nossa experiência com os temas relacionados à saúde. Fraudes e notícias falsas ocorrem também no âmbito de práticas esportivas, como, por exemplo, a invenção de 'jogadores fictícios'. O acompanhamento destes casos nos permitirá entender melhor como os 'fraudadores' exploram de forma estratégica a cadeia alimentar da mídia.

i É importante frisar que a noção de autoridade envolve a formação de uma comunidade de 'profissionais'. Muito embora Zelizer ${ }^{8}$ pense os jornalistas como comunidade de intérpretes, já que os padrões de o que é notícia entre os jornalistas norteamericanos são relativamente compartilhados, a autoridade implica também na forma como os jornalistas defendem suas fronteiras de amadores e diletantes. Daí a questão da formalização das práticas via formação acadêmica, que implica a existência de uma 'ideologia profissional' pela qual os jornalistas tentam defender suas fronteiras. 
Trata-se na realidade de se compreender a existência de circuito comunicativo que, no estudo de Burroughs e Burroughs ${ }^{11}$ se inicia, por exemplo, com a inserção dos dados de um jogador em uma página da Wikipedia.

Depois, com a inserção de comentários sobre a performance do mesmo em fóruns de debates e posts no Facebook até chegar na transcendência desse processo para uma mídia mainstream, como uma revista de futebol. Por último, o ápice do processo, a inclusão do 'atleta' na lista das '50 melhores estrelas em ascensão' deste esporte em 2009 no The Times (Londres). O "sucesso" do processo é interpretado por Burroughs e Burroughs ${ }^{11}$ como a capacidade que tem o "fraudador" de usar a linguagem dos blogs associada à sua capacidade de imitar, quando necessário, "formas jornalísticas tradicionais”ii.

Esse veio também pode ser explorado no noticiário sobre saúde atualmente. Para Carlson ${ }^{12}$, os blogs e outros circuitos podem operar em conjunto e em oposição a veículos estabelecidos no mainstream midiático, sendo importante, então, observar como essa tensão afeta e expõe o lugar até então ocupado pelo sistema do jornalismo profissional nessa temática. Até que ponto blogueiros, em variados graus, produzem e consumem mídia tendo como referência as mídias tradicionais? MacCarthy ${ }^{13}$ sugere que o blog pode ser visto como uma forma dos consumidores de notícias reagirem e criticarem o trabalho das grandes mídias, mas também de se locupletarem dos seus dados e suplementarem as mesmas em prol dos seus interesses.

Em suma, tudo isso envolve a complexa noção da 'participação da audiência' nos processos jornalísticos. Diz respeito à mudança e à convivência dos jornais impressos e televisivos no ambiente online e o impacto que sofrem no seu processo noticioso com a velocidade da internet. Karlsson ${ }^{2}$ defende que esses processos permitem à audiência observar em tempo real os processos de aquisição e apuração de informações. Isto fez com que os conceitos de backstage (bastidor) e frontstage (frente do palco) emergissem no debate, com o jornalismo online dando visibilidade e transparência para os processos de coleta de informação, algo até então improvável no jornal impresso em que o lado visível era apenas o texto acabado. Esta pode ser uma nova vertente de estudo a ser explorada nos estudos de fenômenos como as fake news relacionadas à saúde, tendo em vista a presença de conglomerados de mídia nesse ambiente, nos dando abertura para conhecer a organização, a hierarquização e as formas de funcionamento e rotinas produtivas existentes nesses espaços.

Evidentemente, estamos falando da hipótese de novas formações discursivas se constituírem nesse universo de temas nos quais cada qual das vozes institucionais, como a representada pela Fundação Oswaldo Cruz (Fiocruz), se torna mais uma nessa ampla cadeia comunicativa envolvendo mídias convencionais, sociais e digitais. Várias destas últimas exploram a chamada 'relação direta' entre produtor e consumidor, tema até então associado às retóricas vinculadas aos regimes populistas, possibilitadas não só pelo tempo de produção 'informativa' dedicado por diletantes ao uso dessas plataformas, como também às estratégias e manipulações de algoritmos capazes de ampliar enormemente o arco de recepção dessas 'notícias'.

Isto não significa associar a amplitude da recepção ao impacto que as fake news vêm causando, mas à capacidade de agentes desse universo de outsiders intervirem na produção do processo noticioso. A grande reação do sistema profissional do jornalismo até agora tem sido o uso do fact-checking e, em variados graus, a imputação de censura a quem produz esse tipo de notícia em nome de interesses 'escusos'. Mas acreditamos que as estratégias não serão eficientes se não observarmos o fenômeno com mais cuidado, analisando o seu contexto, o ambiente comunicacional no qual ele ocorre, as redes de informação, as articulações entre agentes diversos, as cadeias produtivas, as formas como são financiadas e como elas impactam, em variados graus, os debates sobre saúde e ciência. É neste sentido que os trabalhos mencionados a seguir trazem suas colaborações.

Explorando as novas disputas por lugar de fala, Teixeira e Santos estudam fake news relacionadas à febre amarela, divulgadas entre 2016 e 2018. Por meio dos textos de posts e áudios por eles analisados, os autores refletem sobre a diluição dos saberes ou do poder de saber do Estado, dos experts e de instituições

ii O nome do jogador era Masal Bugduv, 16 anos, estrela de futebol da Moldávia, que teve seus sonhos realizados quando The Times of London classificou-o como número 30 entre as "50 melhores estrelas em ascensão do futebol" e informou que ele provavelmente iria assinar contrato com o clube de futebol britânico $\operatorname{Arsenal}^{8}(477 ; 486)$. 
que representam a ciência, como a indústria farmacêutica. Também partindo da constatação da crise de autoridade no meio científico, Oliveira, Quinan e Toth propõem um mapeamento da circulação de três disputas de informação científica ligadas à saúde no Facebook: movimento antivacina, fosfoetanolamina e Mineral Miracle Solution (MMS). Neste estudo, eles focam sua atenção nos algoritmos - entendidos como agentes nas disputas de informação - e avaliam as consequências das páginas sugeridas no crescente fluxo de desinformação.

Barreto, Amorim, Garcia e Almeida analisaram as postagens sobre a epidemia de zika na página da Fiocruz no Facebook a partir de sua frequência, enquadramento, formato e engajamento, cruzando as informações postadas com os comentários. Os resultados mostraram o destaque recebido pelo tema na página, bem como a popularidade das postagens sobre boatos, apesar da pouca interação e pouca variação dos formatos noticiosos postados pela Fiocruz. Estudo semelhante fizeram Miola e Marques, ao analisarem as campanhas de comunicação promovidas pelo Ministério da Saúde (MS) sobre o mosquito Aedes aegypti no Facebook, pondo em confronto a comunicação de interesse público (associada a políticas de saúde e a valores democráticos como transparência e participação) e as políticas de imagem de instituições e indivíduos (voltadas para auferir vantagens político-eleitorais), com o objetivo de identificar o grau de instrumentalização dessas campanhas por parte do Estado. Kalsing, Rizzo e Brandão , tendo como objeto de estudo a seção 'Verdade ou Boato' do jornal Zero Hora (meio impresso) e GaúchaZH (meio digital), buscaram compreender as características das matérias produzidas e o perfil das informações nela checadas, além de verificar como os veículos agenciam sua posição de credibilidade em relação às alterações nos modos de produção e circulação de conteúdos no ambiente digital, especialmente na temática da saúde. Os autores constatam como os procedimentos de checagem reforçam o jornalismo profissional como o sistema perito.

O dossiê conta, ainda, com uma entrevista com Afonso de Albuquerque sobre fake news e uma nota de conjuntura escrita por Silvio Waisbord. O professor da Universidade Federal Fluminense critica a adoção no Brasil de modelos norte-americanos como o fact-checking como forma de combate às assim chamada fake news. É preciso considerar que, segundo ele, que essas estratégias são formas autoritárias de reivindicar a autoridade sobre a verdade num contexto de crise do reconhecimento do jornalismo como instância do verdadeiro. $\mathrm{O}$ fenômeno das fake news na saúde pública global reflete mudanças significativas no regime de informações e de produção da verdade, revelando uma transição de uma situação em que a comunidade médica dominou sem dúvida o fluxo de informações em saúde fundamentadas no modelo biomédico para um cenário mais concorrido, competitivo e caótico. Nesse contexto atual, a revolução digital derrubou o antigo regime, transformando a produção, distribuição e consumo em larga escala de informações em saúde. Segundo o professor da George Washington University, consequentemente, a desinformação se espalha, à medida que o público é capaz de obter informações sobre questões de saúde a partir de uma variedade de fontes e plataformas, e atores desonestos inundam a Internet com informações factualmente incorretas, boatos e teorias da conspiração.

Boa leitura! 


\section{Referências}

1. Bock M. Citizen video journalists and authority in narrative: reviving the role of the witness. Journalism. 2011;13(5):639-53. doi: 10.1177/1464884911421703.

2. Karlsson $M$. The immediacy of online news, the visibility of journalistic processes and a restructuring of journalistic authority. Journalism. 2011;12(3):279-95. doi: 10.1177/1464884910388223.

3. Zuckerman E. Fake news is a red herring [Internet]. Bonn: DW Made for Minds; 2017 Jan 01 [cited 2020 jan. 27]. Available from: http://www.dw.com/en/fake-news-is-a-red-herring/a-37269377

4. Boyd D. Did media literacy backfire? [Internet]. New York: Data \& Society, Points; 2017 Jan 05 [cited 2020 jan. 05]. Available from: https://points.datasociety.net/did-media-literacy-backfire-7418c084d88d

5. Caplan R. How do you deal with a problem like "fake news"? [Internet]. New York: Data \& Society, Points; 2017 Jan 05 [cited 2020 jan. 05]. Available from: https://points.datasociety.net/how-do-youdeal-with-a-problem-like-fake-news-80f9987988a9

6. Bolin G. Television journalism, politics, and entertainment: power and autonomy in the field of television journalism. Telev New Media [Internet]. 2014 [cited 2020 Feb 02];15(4):336-49. Available from: https:// doi.org/10.1177/1527476414525671

7. Roxo MA, Melo S. Hiperjornalismo: uma visada sobre fake news a partir da autoridade jornalística. Famecos. 2018;25(3);1-19. doi: 10.15448/1980-3729.2018.3.30572.

8. Neveu E. Sociologia do jornalismo. São Paulo: Loyola; 2005.

9. Zelizer B. Covering the body: the Kennedy assassination, the media, and the shaping of collective memory. Chicago: University of Chicago Press; 1992.

10. Carlson M. Journalistic authority: legitimating news in the digital era. New York: Columbia University Press; 2017.

11. Burroughs B, Burroughs WJ. The Masal Bugduv hoax: football blogging and journalistic authority. New Media. 2011;14(3):476-91.

12. Carlson M. Blogs and journalistic authority. The role of blogs in US Election Day 2004 coverage. Journalism Stud. 2014;8(2):264-79. doi: 10.1080/14616700601148861.

13. McCarthy B. Consuming sports media, producing sports media: An analysis of two fan sports blogospheres. International Review for the Sociology of Sport. 2013;48(4): 421-434. 